Correspondence

Fred A. Rainey

frainey@Isu.edu

\section{Description of four novel psychrophilic, ionizing radiation-sensitive Deinococcus species from alpine environments}

\author{
Ryan P. Callegan, ${ }^{1}$ M. Fernanda Nobre, ${ }^{2}$ Patrick M. McTernan, ${ }^{1}$ \\ John R. Battista, ${ }^{1}$ Rafael Navarro-González, ${ }^{3}$ Christopher P. McKay, ${ }^{4}$ \\ Milton S. da Costa $^{5}$ and Fred A. Rainey ${ }^{1}$ \\ ${ }^{1}$ Department of Biological Sciences, Louisiana State University, Baton Rouge, LA 7080, USA \\ ${ }^{2}$ Departamento de Zoologia, Universidade de Coimbra, 3004-517 Coimbra, Portugal \\ ${ }^{3}$ Laboratorio de Química de Plasmas y Estudios Planetarios, Instituto de Ciencias Nucleares, \\ Universidad Nacional Autónoma de México, Ciudad Universitaria, México DF 04510, Mexico \\ ${ }^{4}$ Space Science Division, NASA Ames Research Center, Moffett Field, CA 94035, USA \\ ${ }^{5}$ Departamento de Bioquímica and Centro de Neurociências e Biologia Celular, Universidade de \\ Coimbra, 3004-517 Coimbra, Portugal
}

Five psychrophilic bacterial strains were isolated from soil samples collected above the treeline of alpine environments. Phylogenetic analysis based on 16S rRNA gene sequences indicated that these organisms represent four novel species of the genus Deinococcus; levels of sequence similarity to the type strains of recognized Deinococcus species were in the range 89.3-94.7\%. Strains PO-04-20-132 ${ }^{\top}$, PO-04-20-144, PO-04-19-125 ${ }^{\top}$, ME-04-01-32 ${ }^{\top}$ and ME-04-04-52 ${ }^{\top}$ grew aerobically, with optimum growth at $10{ }^{\circ} \mathrm{C}$ and at $\mathrm{pH} 6-9$. The major respiratory menaquinone was MK-8. The fatty acid profiles of strains PO-04-20-132 ${ }^{\top}, \mathrm{PO}-04-20-144$, PO-04-19-125 $5^{\top}$ and ME-04-01-32 ${ }^{\top}$ were dominated by $16: 1 \omega 7 c, 17: 0$ iso and $15: 1 \omega 6 c$, whereas $16: 1 \omega 7 c, 17: 0$ cyclo and $16: 0$ predominated in strain ME-04-04-52 ${ }^{\top}$. The DNA G +C contents of strains PO-04-20-132 ${ }^{\top}$, PO-04-19-125 ${ }^{\top}$, ME-04-01-32 ${ }^{\top}$ and ME-04-04-52 ${ }^{\top}$ were 63.2, 63.1, 65.9 and 62.6 mol\%, respectively. Strains PO-04-20-132 ${ }^{\top}, \mathrm{PO}-04-19-125^{\top}$, ME-04-01-32 ${ }^{\top}$ and ME-04-04-52 ${ }^{\top}$ had gamma radiation $D_{10}$ (dose required to reduce the bacterial population by 10 -fold) values of $\leqslant 4 \mathrm{kGy}$. These four strains showed sensitivity to UV radiation and extended desiccation as compared with Deinococcus radiodurans. On the basis of the phylogenetic analyses, and chemotaxonomic and phenotypic data, it is proposed that strains PO-04-20-132 ${ }^{\top}$ (=LMG $24019^{\top}=$ NRRL B-41950 ${ }^{\top}$; Deinococcus radiomollis sp. nov.), PO-04-19-125 ${ }^{\top}$ (=LMG $24282^{\top}=$ NRRL B-41949 ${ }^{\top}$; Deinococcus claudionis sp. nov.), ME-04-01-32 ${ }^{\top}$ (=LMG $24022^{\top}=$ NRRL B-41947 ${ }^{\top}$; Deinococcus altitudinis sp. nov.) and ME-04-04-52 ${ }^{\top}$ (=LMG $24283^{\top}=$ NRRL B-41948 ${ }^{\top}$; Deinococcus alpinitundrae sp. nov.) represent the type strains of four novel species of the genus Deinococcus.
At the time of writing, the genus Deinococcus comprised 25 recognized species, three of which were isolated from

The GenBank/EMBL/DDBJ accession numbers for the $16 \mathrm{~S}$ rRNA gene sequences of strains PO-04-20-132 ${ }^{\top}$, PO-04-20-144, PO-04-19-125 ${ }^{\top}$, ME-04-01-32 ${ }^{\top}$ and ME-04-04-52 ${ }^{\top}$ are EF635404, EF635405, EF635406, EF635407 and EF635408, respectively.

A two-dimensional thin-layer chromatograph of total polar lipids, graphs showing the effect of gamma radiation, UV radiation and desiccation on the survival of the new isolates, and a table detailing the fatty acid compositions of the new isolates and recognized Deinococcus species are available as supplementary material with the online version of this paper. low-temperature environments, namely Antarctic soils or rocks (Hirsch et al., 2004). The optimal growth temperatures of species of the genus Deinococcus fall across a broad range from 9 to $50{ }^{\circ} \mathrm{C}$. The majority of species are reported to have optimal growth temperatures in the mesophilic range. Exceptions are three slightly thermophilic species, namely Deinococcus geothermalis, D. murrayi and D. maricopensis (Ferreira et al., 1997; Rainey et al., 2005), and three psychrophilic species, namely Deinococcus frigens, D. marmoris and D. saxicola (Hirsch et al., 2004).

The most studied characteristic of members of the genus Deinococcus is their ability to survive exposure to ionizing 
radiation and to repair their DNA following damage caused by radiation (gamma or UV) or desiccation. All species of the genus Deinococcus for which the characteristic has been tested have shown resistance to levels of ionizing radiation to which they would never be exposed in the natural environment. The type species of the genus, Deinococcus radiodurans $\left(\right.$ strain $\left.\mathrm{R}^{\mathrm{T}}\right)$, displays a $\mathrm{D}_{10}$ (dose required to reduce the bacterial population by 10 -fold) value of $11.5 \mathrm{kGy}$ following exposure to gamma radiation at a dose rate of $2.57 \mathrm{kGy} \mathrm{h}^{-1}$.

During the course of a study to examine the culturable bacterial diversity in alpine regions, a number of samples were collected from Pico de Orizaba, Mexico, and Mount Evans, CO, USA. These surface (upper $2 \mathrm{~cm}$ ) soil samples were collected by using a sterile scoop from above the treeline at high altitudes $(>3500 \mathrm{~m})$, transported to the laboratory and stored at ambient temperature until processing. The samples were designated PO-04-19 (5002 m), PO-04-20 (5065 m), ME-04-01 (4003 m) and ME-04-04 $(3596 \mathrm{~m})$. Serial dilutions were plated on a number of nutrient growth media, including $1 / 10$-strength plate count agar (PCA; Difco). The dilutions were made in liquid media of the same composition as the agar plates. Plates were incubated at 10 and $25{ }^{\circ} \mathrm{C}$ for up to 40 and 20 days, respectively. CFU values (per gram of soil) for these samples were in the range $3.3 \times 10^{3}-1.73 \times 10^{7}$. Analysis of partial 16S rRNA gene sequences of five of the bacterial strains isolated, designated PO-04-20-132 ${ }^{\mathrm{T}}$, PO-04-20-144, PO-04-19-125 ${ }^{\mathrm{T}}, \mathrm{ME}-04-01-32^{\mathrm{T}}$ and ME$04-04-52^{\mathrm{T}}$, indicated that they were members of the genus Deinococcus, and these were characterized further.

Almost-complete 16S rRNA gene sequences comprising between 1436 and $1440 \mathrm{nt}$ were determined for the five strains as described by Rainey et al. (1996). The 16S rRNA gene sequences were aligned against representative reference sequences of members of the genus Deinococcus and related taxa by using MEGA version 3.1 (Kumar et al., 2004). The method of Jukes \& Cantor (1969) was used to calculate evolutionary distances. Phylogenetic dendrograms were constructed and bootstrap analyses were performed by using algorithms contained in the PHYLIP package (Felsenstein, 1993). Comparison with recognized species of the genus Deinococcus showed that these five novel strains fell within the radiation of this genus and represented two novel lineages (Fig. 1). Levels of $16 \mathrm{~S}$ rRNA gene sequence similarity to the type strains of recognized species of the genus Deinococcus were in the range 89.3-94.7\%. Four of the novel strains, PO-04-20-132 ${ }^{\mathrm{T}}$, PO-04-20-144, PO-04-19-125 $5^{\mathrm{T}}$ and ME-04-01-32 ${ }^{\mathrm{T}}$, formed a coherent cluster supported by a bootstrap value of $100 \%$ whereas the fifth strain, ME-04-04-52 ${ }^{\mathrm{T}}$, represented a distinct and separate lineage (Fig. 1). Strains PO-04-20-132 ${ }^{\mathrm{T}}$ and PO-0420-144 shared $100 \%$ 16S rRNA gene sequence similarity. Levels of $16 \mathrm{~S}$ rRNA gene sequence similarity between the four strains (PO-04-20-132 ${ }^{\mathrm{T}}$, PO-04-20-144, PO-04-19$125^{\mathrm{T}}$ and ME-04-01-32 ${ }^{\mathrm{T}}$ ) clustering together were in the range $96.6-100 \%$. Strain ME-04-04-52 ${ }^{\mathrm{T}}$ had $16 \mathrm{~S}$ rRNA gene

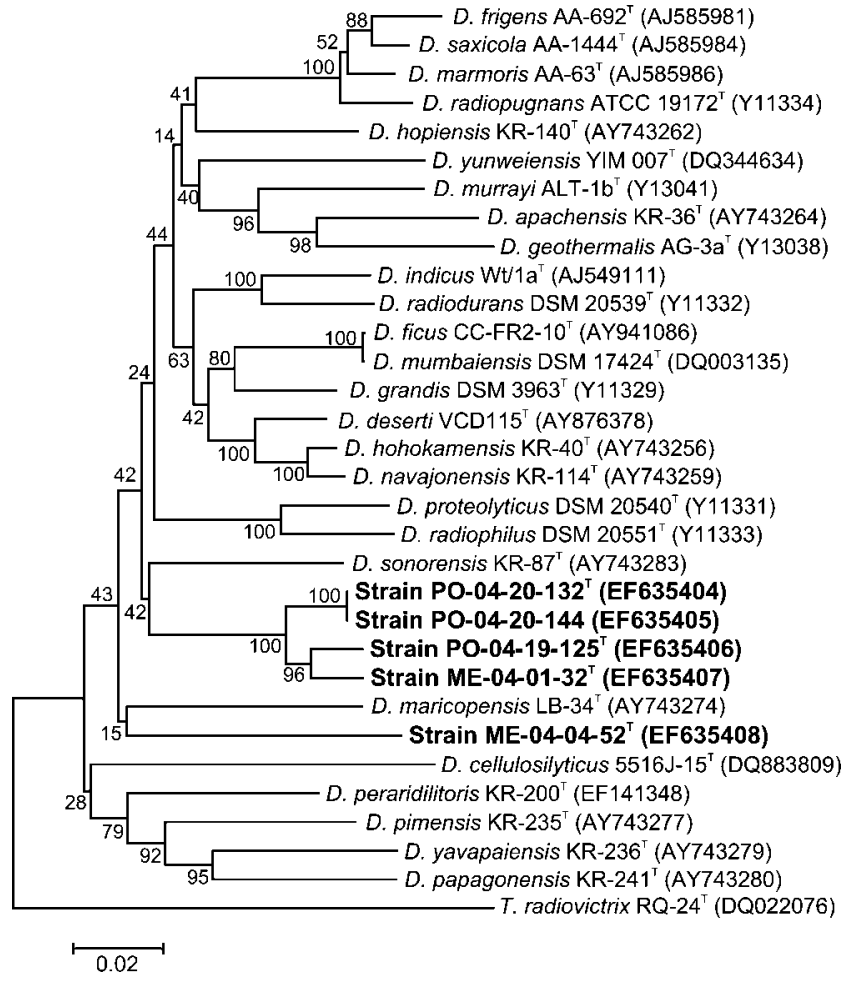

Fig. 1. Phylogenetic tree based on $16 \mathrm{~S}$ rRNA gene sequences showing the relationships of strains ME-04-01-32 ${ }^{\top}$, ME-04-04$52^{\top}, \mathrm{PO}-04-19-125^{\top}, \mathrm{PO}-04-20-132^{\top}$ and PO-04-20-144 and recognized Deinococcus species. The dendrogram was constructed from distance matrices according to the neighbour-joining method. Numbers at branching points represent bootstrap percentages based on 1000 replicates. Truepera radiovictrix $\mathrm{RQ}-24^{\top}$ (Albuquerque et al., 2005) was used as the outgroup. Bar, 2 inferred nucleotide substitutions per 100 nt.

sequence similarities in the range $89.3-93.3 \%$ to the type strains of recognized Deinococcus species. With such low levels of $16 \mathrm{~S}$ rRNA gene sequence similarity to other lineages, the branching point of strain ME-04-04-52 ${ }^{\mathrm{T}}$ was not well supported by bootstrap analyses and it thus represents a well-separated lineage (Fig. 1).

DNA for determination of the genomic $\mathrm{G}+\mathrm{C}$ content was isolated as described by Cashion et al. (1977). The DNA $\mathrm{G}+\mathrm{C}$ contents of strains PO-04-20-132 ${ }^{\mathrm{T}}$, PO-04-19-125 ${ }^{\mathrm{T}}$, ME-04-01-32 ${ }^{\mathrm{T}}$ and ME-04-04-52 ${ }^{\mathrm{T}}$ were determined by HPLC (Mesbah et al., 1989), and was 63.2, 63.1, 65.9 and $62.6 \mathrm{~mol} \%$ respectively. These values are within the range reported for recognized Deinococcus species (59.4$71.1 \mathrm{~mol} \%)$.

Cultures used for polar lipid analysis were grown on nutrient agar (Difco) at $14{ }^{\circ} \mathrm{C}$ for 15 days. Harvesting of cultures, extraction of lipids, two-dimensional TLC, and staining of the plates with molybdophosphoric acid, nynhidrin and $\alpha$-naphthol were performed as described by Prado et al. (1988). Lipoquinones were extracted from 
freeze-dried cells, purified by TLC and separated by HPLC as described by Tindall (1989). Cultures for fatty acid analysis were grown in liquid medium (comprising, per litre: $0.5 \mathrm{~g}$ tryptone, $0.25 \mathrm{~g}$ yeast extract and $0.1 \mathrm{~g}$ glucose; pH 6) in a rotary shaker at 120 r.p.m. for 12 days at $10{ }^{\circ} \mathrm{C}$. Fatty acid methyl esters were obtained from fresh wet biomass by saponification, methylation and extraction as described by Kuykendall et al., (1988), and were separated, identified and quantified as described by Moreira et al. (2000).

Strains PO-04-20-132 ${ }^{\mathrm{T}}$, PO-04-19-125 $5^{\mathrm{T}}, \mathrm{ME}-04-01-32^{\mathrm{T}}$ and ME-04-04-52 $2^{\mathrm{T}}$ had fairly similar polar lipid patterns, consisting primarily of glycophospholipids, aminophospholipids and glycolipids (see Supplementary Fig. S1 available in IJSEM Online). These novel organisms contained one major glycophospholipid with a similar mobility to the well-characterized 2'-O-(1,2-diacyl-sn-glycero-3phospho)-3'-O-( $\alpha$-galactosyl)- $N$-D-glyceroyl alkylamine of D. radiodurans (Anderson \& Hansen, 1985), a major glycolipid and a major aminophospholipid. Other minor polar lipids were also detected in the novel organisms. It is interesting to note that we did not detect aminolipids in the type strain of D. marmoris (Supplementary Fig. S1).

The fatty acid profiles of strains PO-04-20-132 ${ }^{\mathrm{T}}$, PO-04$19-125^{\mathrm{T}}$ and ME-04-01-32 ${ }^{\mathrm{T}}$ were dominated by $16: 1 \omega 7 \mathrm{c}$ $(26.2-36.8 \%), 17: 0$ iso (14.6-19.5\%) and $15: 1 \omega 6 c(6.9-$ $10.9 \%$ ), the combination of which allows these strains to be distinguished from all other recognized species of the genus Deinococcus. However, the fatty acid profiles of these strains were very similar and could not be used to distinguish them from each other. (see Supplementary Table S1 available in IJSEM Online). The fatty acid profile of ME-04-04-52 ${ }^{\mathrm{T}}$, dominated by $17: 0$ cyclo $(33.7 \%)$ and $16: 1 \omega 7 c(38.5 \%)$, allowed this strain to be distinguished from the type strains of all recognized species of the genus Deinococcus, and also from strains PO-04-20-132 ${ }^{\mathrm{T}}$, PO-04$19-125^{\mathrm{T}}$ and ME-04-01-32 ${ }^{\mathrm{T}}$. Moreover, strain ME-04-04$52^{\mathrm{T}}$ lacked branched-chain iso and anteiso fatty acids, which are present in most strains of recognized Deinococcus species.

The vast majority of species of the genus Deinococcus have high levels of unsaturated fatty acids, irrespective of the presence or absence of branched-chain components. The novel strains had lower proportions of saturated short straight-chain or unsaturated chain fatty acids than many other mesophilic or slightly thermophilic species of the genus. The type strains of the psychrophilic species $D$. saxicola and $D$. frigens have, by contrast, extremely high levels of unsaturated fatty acids, but the type strain of the mesophilic species Deinococcus hopiensis also possesses similar levels of these fatty acids. The major respiratory quinone of the five new isolates was menaquinone 8 (MK-8), consistent with data for all other Deinococcus strains.

Cell morphology and motility were examined by phasecontrast microscopy after cultivation on agar plates. Colonies on 1/10-strength PCA were light pink. Cells of the new isolates were Gram-positive but differed in morphology and cell size. Cells of strains PO-04-20-132 ${ }^{\mathrm{T}}$, PO-04-20-144 and ME-04-01-32 ${ }^{\mathrm{T}}$ were rods, 2.4-2.9 $\mu \mathrm{m}$ long and $1.2-1.5 \mu \mathrm{m}$ wide. Coccoid morphology was observed for strain ME-04-04-52 ${ }^{\mathrm{T}}$, cells of which were $2.4 \mu \mathrm{m}$ in diameter. Cells of strain PO-04-19-125 ${ }^{\mathrm{T}}$ were spherical or short rods of $2.3 \times 1.54 \mu \mathrm{m}$. Cells of all the novel strains were non-motile and spores were not observed.

The temperature range for growth was determined on 1/10-strength PCA plates incubated for 10 days at temperatures between 2 and $30{ }^{\circ} \mathrm{C}$. The optimum growth temperature for all five strains was $10{ }^{\circ} \mathrm{C}$, with growth occurring between 5 and $25^{\circ} \mathrm{C}$ but not at 2 or $30{ }^{\circ} \mathrm{C}$. The $\mathrm{pH}$ range for growth was determined at $10{ }^{\circ} \mathrm{C}$ on buffered 1/10-strength PCA plates; the media buffered between $\mathrm{pH} 4$ and $\mathrm{pH} 10$ were prepared as described by Ferreira et al. (1997). Strains PO-04-20-132 ${ }^{\mathrm{T}}$, PO-04-20-144, PO04-19-125 ${ }^{\mathrm{T}}$, ME-04-01-32 ${ }^{\mathrm{T}}$ and ME-04-04-52 ${ }^{\mathrm{T}}$ grew between $\mathrm{pH} 5$ and $\mathrm{pH} 10$ with the exception that strain ME-04-01-32 ${ }^{\mathrm{T}}$ was unable to grow above $\mathrm{pH} 9$.

Tests for catalase, cytochrome oxidase, and hydrolysis of starch, casein and gelatin were performed as described by Smibert \& Krieg (1981). All strains were cytochrome oxidase-negative and catalase-positive. None of the five strains was capable of hydrolysis of starch, casein or gelatin. Single-carbon source assimilation tests were performed in a defined medium solidified with deionized water-washed agar as described by Rainey et al. (2005). Growth was examined visually on plates incubated at $10{ }^{\circ} \mathrm{C}$ for up to 20 days. Negative control plates did not include the carbon source. Positive control cultures were grown on both 1/10strength PCA and solidified Degryse medium 162 (Degryse et al., 1978). The novel strains utilized a number of substrates for growth, and differences in substrate utilization patterns were observed. Complete results of the phenotypic characterization of the novel isolates are provided in Table 1 and in the species descriptions below.

To determine levels of resistance to UV radiation, cells of the new isolates and the type strain of $D$. radiodurans were harvested from 1/10-strength PCA when colonies began to appear and then suspended in the corresponding liquid medium to an $\mathrm{OD}_{600}$ of 0.2 . Aliquots $(1 \mathrm{ml})$ of the suspension were transferred to sterile Petri dishes and exposed to a 254-nm UVLMS-38 (UVP) light source for dosages of 200,400,600, 800 and $1000 \mathrm{~J} \mathrm{~m}^{-2}$. The light source was calibrated by using a J225 (UVP) radiometer to deliver a dose of $630 \mu \mathrm{W} . \mathrm{s} \mathrm{cm}^{-2}$. Following exposure, suspensions of serial dilutions were plated in triplicate and incubated at $10{ }^{\circ} \mathrm{C}$ for the new isolates and at $30{ }^{\circ} \mathrm{C}$ for $D$. radiodurans. Attention was taken to ensure that plates were kept in the dark to avoid photorepair processes. Growth after a maximum of 42 days incubation was compared with that of an unirradiated control to determine the surviving fraction. The survival of isolates after exposure to various doses of gamma radiation was determined by exposing 
Table 1. Differential characteristics between the five novel isolates

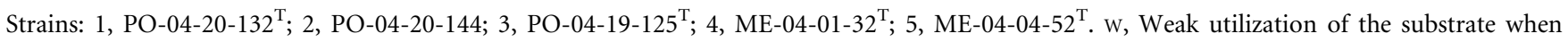
compared with control reactions; ND, not determined.

\begin{tabular}{|c|c|c|c|c|c|}
\hline Characteristic & 1 & 2 & 3 & 4 & 5 \\
\hline Cell morphology & Rods & Rods & Cocci/short rods & Rods & Cocci \\
\hline Cell size $(\mu \mathrm{m})$ & $2.4 \times 1.2$ & $2.7 \times 1.3$ & $2.3 \times 1.5$ & $2.9 \times 1.5$ & 2.4 \\
\hline \multicolumn{6}{|l|}{ Utilization of: } \\
\hline D-Glucose & + & + & + & - & - \\
\hline Fructose & $\mathrm{w}$ & w & + & - & - \\
\hline L-Rhamnose & + & $\mathrm{W}$ & + & - & - \\
\hline L-Arabinose & + & + & + & + & $\mathrm{W}$ \\
\hline Ribose & - & - & - & + & - \\
\hline Sucrose & + & + & + & - & - \\
\hline Xylose & + & + & + & - & - \\
\hline Galactose & + & + & - & + & - \\
\hline
\end{tabular}

aliquots of the strains (prepared as described above for UV exposure) to gamma radiation by using a cobalt- 60 source at a dose rate of $2.57 \mathrm{kGy} \mathrm{h}^{-1}$, as described by Zimmerman \& Battista (2006). The cell suspensions were exposed to doses of 2.5, 5.0, 10.0 and $15.0 \mathrm{kGy}$. Aliquots of cell suspensions not exposed to gamma or UV radiation were maintained at room temperature and serial dilutions were plated at the same time as the exposed cell suspensions. For determination of desiccation resistance, cells were prepared as described for UV radiation exposure. A 100- $\mu$ aliquot of the suspension was spotted onto each well of a polystyrene 24-well microtitre plate and dried completely before placing in a desiccation chamber (Bel-Art). The desiccation chamber was maintained at room temperature. An additional desiccation experiment was performed at $10{ }^{\circ} \mathrm{C}$. Relative humidity was maintained below $5 \%$ throughout, as measured by a $\mathrm{HOBO} \mathrm{H} 8$ (Onset), by using silica gel desiccant (which was replaced weekly). Rehydration was performed after 2, 7, 14, 28 and 42 days by adding $1 \mathrm{ml}$ of the appropriate medium, allowing resuspension of the cells for $30 \mathrm{~min}$, followed by vigorous mixing. Resulting suspensions were dilution plated in triplicate and incubated at the appropriate temperature for a maximum of 42 days. Surviving fractions were calculated from titres before desiccation and after rehydration. $D$. radiodurans $\mathrm{R} 1^{\mathrm{T}}$ (DSM $20539^{\mathrm{T}}$ ) was used as a control in all gamma, UV and desiccation resistance experiments.

In contrast to all other Deinococcus species for which data have been reported, strains PO-04-20-132 ${ }^{\mathrm{T}}$, PO-04-19$125^{\mathrm{T}}, \mathrm{ME}-04-01-32^{\mathrm{T}}$ and ME-04-04-52 ${ }^{\mathrm{T}}$ showed sensitivity to gamma and UV radiation as well as prolonged desiccation (see Supplementary Fig. S2 in IJSEM Online). The $D_{10}$ values for each of these stresses are provided for four of the five new isolates as well as for $D$. radiodurans $R 1^{\mathrm{T}}$ (Table 2). From the $\mathrm{D}_{10}$ values for gamma and UV radiation exposure and prolonged desiccation it is clear that the novel strains are significantly more sensitive to these stresses as compared with $D$. radiodurans. The most sensitive strain was PO-04-20-132 ${ }^{\mathrm{T}}$ with $\mathrm{D}_{10}$ values of $2.2 \mathrm{kGy}$ and $220 \mathrm{~J} \mathrm{~m}^{-2}$ for gamma and UV radiation, respectively. No significant difference in $\mathrm{D}_{10}$ values was observed when the desiccation experiment was performed at $10{ }^{\circ} \mathrm{C}$ (data not shown).

The strains isolated in the present study can be differentiated from recognized species of the genus Deinococcus on the basis of their phylogenetic position. They have been shown to fall into two distinct lineages, one comprising strains PO-04-20-132 ${ }^{\mathrm{T}}, \mathrm{PO}-04-20-144, \mathrm{PO}-04-19-125^{\mathrm{T}}$ and ME-04-01-32 ${ }^{\mathrm{T}}$ and the other strain ME-04-04-52 ${ }^{\mathrm{T}}$. Levels of $16 \mathrm{~S}$ rRNA gene sequence similarity between these strains and the type strains of recognized Deinococcus species were less than $95 \%$ and as low as $87.9 \%$, indicating that they do not belong to any of the established phylogenetic clusters within the genus. The novel strains were psychrophilic, as with $D$. frigens, D. marmoris and D. saxicola, but our

Table 2. $D_{10}$ values for the strains isolated in the present study as compared with $D$. radiodurans after exposure to gamma and UV radiation and prolonged conditions of desiccation

Strains: 1 , D. radiodurans $\mathrm{R} 1^{\mathrm{T}} ; 2$, PO-04-19- $125^{\mathrm{T}} ; 3$, PO-04-20-132 ${ }^{\mathrm{T}}$; 4, ME-04-01-32 ${ }^{\mathrm{T}} ; 5$, ME-04-04-52 ${ }^{\mathrm{T}}$.

\begin{tabular}{|c|c|c|c|c|c|}
\hline & 1 & 2 & 3 & 4 & 5 \\
\hline Gamma (kGy) & 11.5 & 3.6 & 2.2 & 3.8 & 4.0 \\
\hline $\mathrm{UV}\left(\mathrm{J} \mathrm{m}^{-2}\right)$ & 870 & 310 & 220 & 550 & 690 \\
\hline Desiccation (days) & $>42$ & 11.7 & 8.7 & 2 & 1.8 \\
\hline
\end{tabular}


phylogenetic analyses showed that these strains and species shared no close relationship. The new isolates thus represent two new lineages of psychrophiles within the Deinococcus lineage. The novel strains can be clearly differentiated from other Deinococcus species on the basis of their fatty acid profiles. Strains PO-04-20-132 ${ }^{\mathrm{T}}$, PO-0420-144, PO-04-19-125 ${ }^{\mathrm{T}}$ and ME-04-01-32 ${ }^{\mathrm{T}}$ have high levels of $16: 1 \omega 7 c, 17: 0$ iso and $15: 1 \omega 6 c$ fatty acids whereas strain ME-04-04-52 ${ }^{\mathrm{T}}$ has a unique fatty acid profile containing high levels of 17:0 cyclo (Supplementary Table S1).

Strains PO-04-20-132 ${ }^{\mathrm{T}}$, PO-04-19-125 ${ }^{\mathrm{T}}$ and ME-04-01-32 ${ }^{\mathrm{T}}$ cluster together, with $16 \mathrm{~S}$ rRNA gene sequence similarities in the range 96.6-97.3\%. Although these values could be considered to be relatively high for comparisons between the majority of species of the genus Deinococcus, the novel strains can be differentiated on the basis of phenotypic characteristics, including cell morphology (rods for strains PO-04-20-132 ${ }^{\mathrm{T}}$ and ME-04-01-32 ${ }^{\mathrm{T}}$, short-rods/cocci for strain PO-04-19-125 ${ }^{\mathrm{T}}$ ) and differences in substrate utilization patterns (Table 1). Strain ME- $04-04-52^{\mathrm{T}}$ is not only phylogenetically distinct from the other new isolates but has a unique fatty acid profile containing high levels of 17:0 cyclo. In addition, it can be distinguished from the other isolates by its limited substrate utilization pattern and coccoid cell morphology.

On the basis of these phylogenetic, phenotypic and chemotaxonomic properties, we suggest that strains $\mathrm{PO}-$ 04-20-132 $2^{\mathrm{T}}$, PO-04-19-125 $5^{\mathrm{T}}$, ME-04-01-32 ${ }^{\mathrm{T}}$ and ME-0404-52 ${ }^{\mathrm{T}}$ represent four novel psychrophilic, ionizing radiation-sensitive species of the genus Deinococcus, for which the names Deinococcus radiomollis sp. nov., Deinococcus claudionis sp. nov., Deinococcus altitudinis sp. nov. and Deinococcus alpinitundrae sp. nov., respectively, are proposed.

\section{Description of Deinococcus radiomollis sp. nov. Callegan, da Costa and Rainey}

Deinococcus radiomollis (ra.di'o.mol'lis. L. n. radius a ray; L. adj. mollis soft, susceptible; N.L. masc adj. radiomollis susceptible to radiation).

Forms rod-shaped cells $2.4-2.7 \mu \mathrm{m}$ long and $1.2-1.3 \mu \mathrm{m}$ wide. Gram-positive. Cells are non-motile; spores are not observed. Colonies on 1/10-strength PCA medium are pink-pigmented. Growth occurs between 5 and $25{ }^{\circ} \mathrm{C}$ but not at 2 or $30{ }^{\circ} \mathrm{C}$. Optimum growth temperature is $10{ }^{\circ} \mathrm{C}$. Grows between $\mathrm{pH} 5$ and 10.0. Optimum $\mathrm{pH}$ for growth is 6.0-9.0. Cytochrome oxidase-negative and catalase-positive. The fatty acid profile is dominated by $16: 1 \omega 7 c, 17: 0$ iso and $15: 1 \omega 6 c$. Utilizes L-arabinose, cellobiose, galactose, D-glucose, fructose, mannose, L-rhamnose, sucrose, trehalose, xylose, glucosamine and glycerol. The following substrates are not utilized: melibiose, lactose, raffinose, ribose, sorbose, acetate, citrate, glutamate, $\alpha$-ketoglutarate, lactate, malate, aspartate, cysteine, alanine, asparagine, glutamine, glycine, lysine, methionine, ornithine and proline. Starch, casein and gelatin are not degraded. The DNA $\mathrm{G}+\mathrm{C}$ content of the type strain is $63.2 \mathrm{~mol} \%$. Sensitive to gamma and UV radiation and desiccation as compared with other species of the genus.

The type strain, PO-04-20-132 ${ }^{\mathrm{T}}\left(=\mathrm{LMG} 24019^{\mathrm{T}}=\mathrm{NRRL}\right.$ B- $\left.41950^{\mathrm{T}}\right)$, was isolated from an alpine soil at $5065 \mathrm{~m}$ on Pico de Orizaba, Mexico. Strain PO-04-20-144 (=LMG $24018=$ NRRL B-41951) has been deposited as a reference strain of this species.

\section{Description of Deinococcus claudionis sp. nov. Callegan, da Costa and Rainey}

Deinococcus claudionis (clau.di.o' nis. N.L. gen. n. claudionis of Claudio, named after Gerardo Claudio Sanchez, a Mexican conservationist).

Forms spherical or short rod-shaped cells $2.3 \mu \mathrm{m}$ long and $1.5 \mu \mathrm{m}$ wide. Gram-positive. Cells are non-motile; spores are not observed. Colonies on 1/10-strength PCA medium are pink-pigmented. Growth occurs between 5 and $25{ }^{\circ} \mathrm{C}$ but not at 2 or $30{ }^{\circ} \mathrm{C}$. Optimum growth temperature is $10{ }^{\circ} \mathrm{C}$. Grows between $\mathrm{pH} 5$ and 10.0. Optimum $\mathrm{pH}$ for growth is 6.0-9.0. Cytochrome oxidase-negative and catalase-positive. The fatty acid profile is dominated by $16: 1 \omega 7 c, 17: 0$ iso and $15: 1 \omega 6 c$. Utilizes L-arabinose, cellobiose, fructose, D-glucose, mannose, L-rhamnose, sucrose, trehalose, xylose, glycerol and glucosamine. The following substrates are not utilized: galactose, melibiose, lactose, raffinose, ribose, sorbose, acetate, citrate, glutamate, $\alpha$-ketoglutarate, lactate, malate, aspartate, asparagine, cysteine, alanine, glutamine, glycine, lysine, methionine, ornithine and proline. Starch, casein and gelatin are not degraded. The DNA $\mathrm{G}+\mathrm{C}$ content of the type strain is $63.1 \mathrm{~mol} \%$. Sensitive to gamma and UV radiation and desiccation as compared with other species of the genus.

The type strain, PO-04-19-125 $5^{\mathrm{T}}\left(=\mathrm{LMG} 24282^{\mathrm{T}}=\mathrm{NRRL}\right.$ $\left.\mathrm{B}-41949^{\mathrm{T}}\right)$, was isolated from an alpine soil at $5002 \mathrm{~m}$ on Pico de Orizaba, Mexico.

\section{Description of Deinococcus altitudinis sp. nov. Callegan, da Costa and Rainey}

Deinococcus altitudinis (al.ti.tu'di.nis. L. n. altitudo altitude; L. gen. n. altitudinis of altitude).

Forms rod-shaped cells $2.9 \mu \mathrm{m}$ long and $1.5 \mu \mathrm{m}$ wide. Gram-positive. Cells are non-motile; spores are not observed. Colonies on 1/10-strength PCA medium are pink-pigmented. Growth occurs between 5 and $25^{\circ} \mathrm{C}$ but not at 2 or $30{ }^{\circ} \mathrm{C}$. Optimum growth temperature is $10{ }^{\circ} \mathrm{C}$. Grows between $\mathrm{pH} 5$ and 9.0. Optimum $\mathrm{pH}$ for growth is 6.0-8.0. Cytochrome oxidase-negative and catalase-positive. The fatty acid profile is dominated by $16: 1 \omega 7 c, 17: 0$ iso and $15: 1 \omega 6 c$. Utilizes L-arabinose, cellobiose, galactose, trehalose, glycerol and ribose. The following substrates are not utilized: D-glucose, fructose, L-rhamnose, mannose, melibiose, lactose, raffinose, sorbose, sucrose, xylose, 
acetate, citrate, $\alpha$-ketoglutarate, lactate, malate, aspartate, cysteine, glutamate, alanine, asparagine, glutamine, glucosamine, glycine, lysine, methionine, ornithine and proline. Starch, casein and gelatin are not degraded. The DNA $\mathrm{G}+\mathrm{C}$ content of the type strain is $65.9 \mathrm{~mol} \%$. Sensitive to gamma and UV radiation and desiccation as compared with other species of the genus.

The type strain, ME-04-01-32 ${ }^{\mathrm{T}}\left(=\mathrm{LMG} 24022^{\mathrm{T}}=\right.$ NRRL B$\left.41947^{\mathrm{T}}\right)$, was isolated from an alpine soil at $4003 \mathrm{~m}$ on Mount Evans, CO, USA.

\section{Description of Deinococcus alpinitundrae sp. nov. Callegan, da Costa and Rainey}

Deinococcus alpinitundrae (al.pi.ni.tun'dra.e. L. adj. alpinus alpine; N.L. n. tundra the tundra; N.L. gen. n. alpinitundrae of the alpine tundra, of the treeless region above the treeline of high mountains).

Forms spherical cells $\sim 2.4 \mu \mathrm{m}$ in diameter. Gram-positive. Cells are non-motile; spores are not observed. Colonies on 1/10-strength PCA medium are pink-pigmented. Growth occurs between 5 and $25{ }^{\circ} \mathrm{C}$ but not at 2 or $20{ }^{\circ} \mathrm{C}$. Optimum growth temperature is $10{ }^{\circ} \mathrm{C}$. Grows between pH 5 and 9.0. Optimum pH for growth is 6.0-9.0. Cytochrome oxidase-negative and catalase-positive. The fatty acid profile is dominated by $16: 1 \omega 7 c, 17: 0$ cyclo and $16: 0$. Utilizes L-arabinose, cellobiose, trehalose and glycerol. The following substrates are not utilized: Dglucose, fructose, galactose, L-rhamnose, melibiose, lactose, mannose, raffinose, ribose, sorbose, sucrose, xylose, acetate, citrate, $\alpha$-ketoglutarate, lactate, malate, aspartate, cysteine, alanine, glutamine, glycine, lysine, methionine, glucosamine, glutamate, asparagine, ornithine and proline. Starch, casein and gelatin are not degraded. The DNA $\mathrm{G}+\mathrm{C}$ content of the type strain is $62.6 \mathrm{~mol} \%$. Sensitive to gamma and UV radiation and desiccation as compared with other species of the genus.

The type strain, ME-04-04-52 ${ }^{\mathrm{T}}$ (=LMG $24283^{\mathrm{T}}=\mathrm{NRRL}$ B- $\left.41948^{\mathrm{T}}\right)$, was isolated from an alpine soil sample at $3596 \mathrm{~m}$ on Mount Evans, CO, USA.

\section{Acknowledgements}

F. A. R. was supported by a NASA-Ames/LSU Cooperative Agreement (NCC 2-5469). R. P. C. was supported by a NASA Graduate Student Research Program (NNA-A0HCK72H). R. N.-G. was supported by UNAM-DGAPA IN101903. We wish to thank Jean Euzéby, Laboratoire de Bactériologie École Nationale Vétérinaire Toulouse, France, for providing the etymology of the species epithets.

\section{References}

Albuquerque, L., Simoes, C., Nobre, M. F., Pino, N. M., Battista, J. R., Silva, M. T., Rainey, F. A. \& da Costa, M. S. (2005). Truepera radiovictrix gen. nov., sp. nov., a new radiation resistant species and the proposal of Trueperaceae fam. nov. FEMS Microbiol Lett 247, $161-169$
Anderson, R. \& Hansen, K. (1985). Structure of a novel phosphoglycolipid from Deinococcus radiodurans. J Biol Chem 260, 12219-12223.

Cashion, P., Holder-Franklin, M. A., McCully, J. \& Franklin, M. (1977). A rapid method for the base ratio determination of bacterial DNA. Anal Biochem 81, 461-466.

de Groot, A., Chapon, V., Servant, P., Christen, R., Fischer-Le Saux, M., Sommer, S. \& Heulin, T. (2005). Deinococcus deserti sp. nov., a gammaradiation-tolerant bacterium from the Sahara Desert. Int J Syst Evol Microbiol 55, 2441-2446.

Degryse, E., Glansdorff, N. \& Pierard, A. (1978). A comparative analysis of extreme thermophilic bacteria belonging to the genus Thermus. Arch Microbiol 177, 189-196.

Felsenstein, J. (1993). PHYLIP (phylogeny inference package), version 3.5.1. Distributed by the author. Department of Genome Sciences, University of Washington, Seattle, USA.

Ferreira, A. C., Nobre, M. F., Rainey, F. A., Silva, M. T., Wait, R., Burghardt, J., Chung, A. P. \& da Costa, M. S. (1997). Deinococcus geothermalis sp. nov. and Deinococcus murrayi sp. nov., two extremely radiation-resistant and slightly thermophilic species from hot springs. Int J Syst Bacteriol 47, 939-947.

Hirsch, P., Gallikowski, C. A., Siebert, J., Peiss, K., Kroppenstedt, R., Schumann, P., Stackebrandt, E. \& Anderson, R. (2004). Deinococcus frigens sp. nov., Deinococcus saxicola sp. nov., and Deinococcus marmoris sp. nov., low temperature and draught-tolerating, UVresistant bacteria from continental Antarctica. Syst Appl Microbiol 27, 636-645.

Jukes, T. H. \& Cantor, C. R. (1969). Evolution of protein molecules. In Mammalian Protein Metabolism, vol. 3, pp. 21-132. Edited by H. N. Munro. New York: Academic Press.

Kumar, S., Tamura, K. \& Nei, M. (2004). MEGA3: integrated software for Molecular Evolutionary Genetics Analysis and sequence alignment. Brief Bioinform 5, 150-163.

Kuykendall, L. D., Roy, M. A., O’Neill, J. J. \& Devine, T. E. (1988). Fatty acids, antibiotic resistance, and deoxyribonucleic acid homology groups of Bradyrhizobium japonicum. Int J Syst Bacteriol 38, 358-361.

Lai, W.-A., Kämpfer, P., Arun, A. B., Shen, F.-T., Huber, B., Rekha, P. D. \& Young, C.-C. (2006). Deinococcus ficus sp. nov., isolated from the rhizosphere of Ficus religiosa L. Int J Syst Evol Microbiol 56, 787-791.

Mesbah, M., Premachandran, U. \& Whitman, W. B. (1989). Precise measurement of the $\mathrm{G}+\mathrm{C}$ content of deoxyribonucleic acid by highperformance liquid chromatography. Int J Syst Bacteriol 39, 159-167.

Moreira, C., Rainey, F. A., Nobre, M. F., da Silva, M. T. \& da Costa, M. S. (2000). Tepidimonas ignava gen. nov., sp. nov., a new chemolithoheterotrophic and slightly thermophilic member of the $\beta$-Proteobacteria. Int J Syst Evol Microbiol 50, 735-742.

Prado, A., da Costa, M. S. \& Madeira, V. M. C. (1988). Effect of growth temperature on the lipid composition of two strains of Thermus sp. J Gen Microbiol 134, 1653-1660.

Rainey, F. A., Ward-Rainey, N., Kroppenstedt, R. M. \& Stackebrandt, E. (1996). The genus Nocardiopsis represents a phylogenetically coherent taxon and a distinct actinomycete lineage: proposal of Nocardiopsaceae fam. nov. Int J Syst Bacteriol 46, 1088-1092.

Rainey, F. A., Ray, K., Ferreira, M., Gatz, B. Z., Nobre, N. F., Bagaley, D., Rash, B. A., Park, M.-J., Earl, A. M. \& other authors (2005). Extensive diversity of ionizing-radiation-resistant bacteria recovered from a Sonoran Desert soil and the description of nine new species of the genus Deinococcus from a single soil sample. Appl Environ Microbiol 71, 5225-5235.

Rainey, F. A., Ferreira, M., Nobre, M. F., Ray, K., Bagaley, D., Earl, A. M., Battista, J. R., Gómez-Silva, B., McKay, C. P. \& da Costa, M. S. (2007). Deinococcus peraridilitoris sp. nov., isolated from a coastal desert. Int J Syst Evol Microbiol 57, 1408-1412. 
Smibert, R. M. \& Krieg, N. R. (1981). General characterization. In Manual of Methods for General Microbiology, pp. 409-443. Edited by P. Gerhardt, R. G. E. Murray, R. N. Costilow, E. W. Nester, W. A. Wood, N. R. Krieg \& G. B. Phillips. Washington, DC: American Society for Microbiology.

Tindall, B. J. (1989). Fully saturated menaquinones in the archaebacterium Pyrobaculum islandicum. FEMS Microbiol Lett 60, 251-254.
Zhang, Y. Q., Sun, C. H., Li, W. J., Yu, L. Y., Zhou, J. Q., Zhang, Y. Q., Xu, L. H. \& Jaing, C. L. (2007). Deinococcus yunweiensis sp. nov., a gamma- and UV-radiation-resistant bacterium from China. Int J Syst Evol Microbiol 57, 370-375.

Zimmerman, J. M. \& Battista, J. R. (2006). Measuring survival in microbial populations following exposure to ionizing radiation. In Extremophiles, Methods in Microbiology, vol. 35, pp. 745-754. Edited by F. A. Rainey \& A. Oren. London: Academic Press. 